
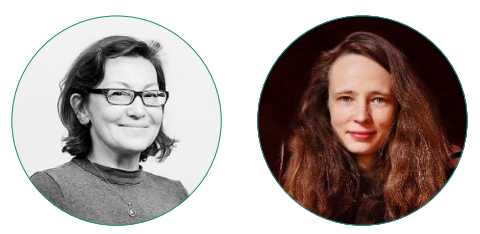

И. М. Козина, Е. В. Серёжкина

\title{
ОЦЕНКА ПСИХОСОЦИАЛЬНЫХ РИСКОВ И КАЧЕСТВО ТРУДОВОЙ ЖИЗНИ РОССИЙСКИХ ПРОФЕССИОНАЛОВ
}

\section{Правильная ссылка на статью:}

Козина И.М., Серёжкина Е.В. Оценка психосоциальных рисков и качество трудовой жизни российских профессионалов // Мониторинг общественного мнения: экономические и социальные перемены. 2021. № 3. С. 21-40. https://doi.org/10.14515/ monitoring.2021.3.1891.

\section{For citation:}

Kozina I. M., Serezhkina E.V. (2021) Measuring Psychosocial Risks and Quality of Work Life Among Russian Professionals. Monitoring of Public Opinion: Economic and Social Changes. No. 3. P. 21-40. https://doi.org/10.14515/monitoring.2021.3.1891. (In Russ.) 
ОЦЕНКА ПСИХОСОЦИАЛЬНЫХ РИСКОВ И КАЧЕСТВО ТРУДОВОЙ ЖИЗНИ РОССИЙСКИХ ПРОФЕССИОНАЛОВ

КОЗИНА Ирина Марксовна - кандидат социологических наук, профессор департамента социологии факультета социальных наук, Национальный исследовательский университет «Высшая школа экономики", Москва, Россия E-MAIL: ikozina@hse.ru https://orcid.org/0000-0001-9595-0460

СЕРЁЖКИНА Екатерина Васильевнакандидат социологических наук, старший преподаватель департамента социологии факультета социальных наук, Национальный исследовательский университет "Высшая школа экономики", Москва, Россия

E-MAIL: katerinaserezhkina@gmail.com https://orcid.org/0000-0002-7730-2758

Аннотация. Статья посвящена анализу потенциала измерительных возможностей психосоциальных рисков в контексте общей оценки качества трудовой жизни российских профессионалов. Предложена система индексов, характеризующая степень выраженности психосоциальных рисков в организационной среде. Эмпирическая часть работы основана на данных стандартизированного опроса 1100 специалистов российских бизнес-организаций, представляющих четыре группы профессиональных занятий: 1) специалисты в области техники, 2) IT-специалисты, 3) специалисты в сфере финансов, 4) специалисты в области администрирования, связей с общественностью, сбыта и маркетинга. Результаты исследования показывают, что традиционные индикаторы субъективного благопо-
MEASURING PSYCHOSOCIAL RISKS AND QUALITY OF WORK LIFE AMONG RUSSIAN PROFESSIONALS

Irina M. KOZINA1 - Cand. Sci. (Soc.), Professor at the Faculty of Social Sciences E-MAIL: ikozina@hse.ru https://orcid.org/0000-0001-9595-0460

Ekaterina V. SEREZHKINA ${ }^{1}$ - Cand. Sci. (Soc.), Senior Lecturer at the Faculty of Social Sciences

E-MAIL: katerinaserezhkina@gmail.com https://orcid.org/0000-0002-7730-2758

\footnotetext{
${ }^{1}$ HSE University, Moscow, Russia
}

Abstract. The paper discusses the potential of measuring psychosocial risks while estimating overall quality of working life among Russian professionals. The authors propose the system of psychosocial indices characterizing the degree of psychosocial risks in the working environment. Empirical base of the study consists of the standardized survey of 1100 specialists in the business sector coming from four categories: technology, IT, finance, and marketing/HR. The study shows that traditional indicators of work life quality (e.g., job satisfaction) might be insufficient, while proposed psychosocial indices allow to assess it more deeply. Following the JD-R model developed by Bakker and Demerouti, the authors select the aspects involving interpersonal relations between co-workers, the content of the work, as well as the balance between personal and corpo- 
лучия сотрудников (удовлетворенность трудом и пр.) могут быть недостаточными для характеристики качества трудовой жизни, в то время как индексы психосоциальных рисков позволяют более комплексно диагностировать трудовую ситуацию. Основываясь на концепции требований-ресурсов (JDR model) A. Бэккера и Е. Демерути, авторы выделяют аспекты, связанные со взаимоотношениями между сотрудниками, содержанием труда и балансом индивидуальных и корпоративных ценностей, как ресурсы, способные «буферизовать" такие требования организационной среды, как низкая степень автономии на рабочем месте, повышенная интенсивность труда и нестабильность рабочей ситуации. Именно социальные аспекты играют значимую роль в процессе компенсации негативных факторов организационной среды, формируя относительно высокий уровень субъективного благополучия. Диагностика психосоциальных рисков позволяет выявлять "красные зоны", нуждающиеся в более пристальном внимании, и, по мнению авторов, должна входить в практики управления персоналом, направленные на предотвращение профессионального выгорания и стресса, влекущих за собой серьезные последствия как для сотрудников, так и для организации.

Ключевые слова: качество трудовой жизни, психосоциальные риски, рабочая среда, удовлетворенность работой, управление персоналом rate values as resources that can buffer such demands of the organizational environment as a low degree of autonomy, increased work intensity and instability of the working environment. In this respect, the psychosocial aspects play the main role in balancing negative factors and forming high subjective working life satisfaction. The authors conclude that the detection of "red zones" of psychosocial risks requiring close attention should be an essential management practice in order to prevent professional stress and its consequences affecting both the workers and the company.

Keywords: quality of work life, psychosocial risks, work environment, job satisfaction, human resources management

\section{Введение}

Концепция качества трудовой жизни предполагает комплексный анализ условий работы с позиции самих работников. Объяснительный потенциал этого понятия заключается в том, что, с одной стороны, оно отражает специфику 
трудовых отношений и повседневных взаимодействий на уровне организации, а с другой - характеризует уровень социального благополучия в сфере труда как важной составляющей качества жизни в целом [Gogoleva, Sorokin, Efendiev, 2017]. Представленные в литературе исследования по проблемам оценки качества трудовой жизни нацелены на поиск и разработку индикаторов, которые отражали бы наиболее важные аспекты работы и трудовых отношений. В условиях многообразия и динамичности современной сферы труда проблемы выявления и отбора таких универсальных характеристик вызывают многочисленные дискуссии (по некоторым оценкам, существует более двадцати различных вариантов построения системы индикаторов, по которым диагностируется производственная ситуация [Munoz de Bustillo et al., 2011: 2]. Наиболее известны разработанные в рамках MOT концепция и индикаторы "достойного труда" [ILO, 2012], которые сегодня используются в международных и национальных мониторингах для оценки качества занятости на макроуровне с учетом отраслевой, гендерной, возрастной и региональной специфики. Масштабные исследования ведутся и в рамках ОЭСР. В аналитическом отчете этой организации отмечается, что в последние годы удалось существенно продвинуться в определении методологических подходов и рамок исследований: были выделены и обозначены основные параметры, подлежащие измерению [OECD, 2013: 150].

Рекомендованные показатели можно разделить на две группы. Аспекты трудовой ситуации, включаемые в первую из них (надежность рабочего места и трудовых доходов, оплату труда, доступ к социальным гарантиям, возможности профессионального и карьерного развития и пр.), идентифицируют степень защищенности работников от рисков прекаризации, и их влияние на социальное самочувствие работников остается наиболее явным и прямым. Вторая группа показателей (санитарно-гигиенические условия, режимы труда, трудовая нагрузка, взаимоотношения на работе и пр.) характеризует качество рабочей среды (work environment) с точки зрения рисков для здоровья и работоспособности сотрудников. В этом плане наибольшую сложность представляет учет воздействия новых факторов, вызванных существенными изменениями социально-организационных контекстов работы. Эксперты в области безопасности труда уже давно обращают внимание на рост рисков для физического и психического здоровья работников из-за внедрения технологических и бизнес-процессов, ведущих к повышению интенсивности труда, усилению контроля, требований к личной эффективности, размыванию границ рабочего времени, росту конкуренции между сотрудниками и пр. В совокупности с рисками прекаризации действие этих факторов способствует формированию достаточно агрессивной рабочей среды, где повышенное напряжение и стресс становятся привычным атрибутом самых разных видов трудовой деятельности.

Показательно, что в отношении данных факторов можно говорить об изменении терминологии: определяемые ранее как факторы стресса, в современной научной литературе они часто обозначаются как социо-психологические факторы и - чаще - психосоциальные риски. Под психосоциальными рисками понимаются такие аспекты организации труда и управления производством и его социальными и организационными условиями, которые могут наносить физический или психо- 
логический ущерб работникам [ILO, 2016: 5]. В западной (особенно европейской) традиции концепт психосоциальных рисков имеет достаточно устоявшуюся структуру и операционализацию: индикаторы риска используются в оценке условий и качества трудовой жизни на национальном и международном уровне [Beque et al., 2017; Burr et al., 2019; Wännström, 2009]. В России, где вопросы психологической безопасности работников пока не вошли в актуальную "повестку" государственной и корпоративной политики в сфере охраны труда, изучение психосоциальных рисков с позиции оценки качества трудовой жизни является сравнительно новым направлением. В последние годы появился ряд социологических публикаций, посвященных проблемам рабочего стресса в отдельных профессиях - в основном связанных с постоянной коммуникацией с людьми (преподаватели вузов, учителя, социальные работники и пр.) [Давыдова, Козьмина, 2014; Абрамов, Груздев, Терентьев, 2019; Константиновский, Пинская, Звягинцев, 2019; Смолева, 2020]. Гораздо реже в фокусе внимания исследователей оказываются представители других профессий - IT-специалисты [Козина, Сережкина, 2019], банковские служащие [Качановецкая, 2015].

В данной работе мы обращаемся к обоснованию и оценке факторов организационного характера, отвечающих за эмоциональное и социально-психологическое благополучие современных работников, применительно к анализу качества трудовой жизни российских профессионалов.

Специалисты высокой квалификации (профессионалы) благодаря своим знаниям и умениям более устойчивы к рискам прекаризации и по целому ряду показателей качества трудовой жизни (возможности профессиональной самореализации, содержательно интересная работа и др.) находятся в относительно привилегированном положении [Тихонова, 2020; Балабанова, 2016; Соболева, Чадова, 2013]. В то же время "ценой" этих преимуществ могут стать эмоциональнопсихологические перегрузки, обусловленные интенсификацией производственных процессов, усилением межличностной напряженности на работе, вызванной высокой конкуренцией за "хорошие" рабочие места и пр. [Балабанова, 2016]. Косвенным подтверждением этому служат данные социальной статистики, согласно которым сегодня каждый четвертый российский профессионал испытывает постоянное напряжение и стресс в течение всего или большей части рабочего времени. Среди укрупненных категорий, занятых в экономике (без привязки к профессии), специалисты высшего уровня квалификации наряду с руководителями и рабочими по обслуживанию установок и машин образуют группу риска труда с повышенной психологической нагрузкой ${ }^{1}$.

Эмпирическую базу работы составили данные опроса специалистов российских бизнес-организаций ${ }^{2}$. В выборочную совокупность вошли специалисты с высшим образованием, не занимающие руководящих должностей (не более двух подчиненных) и представляющие четыре группы: 1) специалисты в области техники:

\footnotetext{
1 Росстат: Комплексное наблюдение условий жизни населения - 2018. URL: https://rosstat.gov.ru/free_doc/new_site/ KOUZ18/index.html (дата обращения:20.06.2021).

2 Опрос проводился в сентябре-ноябре 2018 г. в рамках программы фундаментальных исследований НИу ВшЭ (исследовательский проект «От индустриального к постиндустриальному труду-основные типы трудового поведения российских работников: факторы формирования, проблемы, противоречия»).
} 
инженеры и техники высшей квалификации (условно обозначим их "ИТР"), 2) специалисты по информационным и коммуникационным технологиям: разработчики, администраторы баз данных и т.д. ("IT-специалисты”), 3) специалисты в сфере финансовой деятельности: бухгалтеры, финансовые аналитики, консультанты, оценщики (“бухгалтеры»), 4) специалисты в области администрирования, связи с общественностью, сбыта и маркетинга продукции и услуг ("менеджеры»).

Опрос проводился во всех административных округах (за исключением Крыма), общий объем выборки составил 1110 человек. Для отбора респондентов была сформирована квотная выборка, где размер квот определялся с учетом численности занятых в указанных профессиональных группах в десяти ключевых секторах экономики. В соответствии с квотами наибольшее количество респондентов на момент опроса были заняты на предприятиях обрабатывающей промышленности (18\%), в оптовой и розничной торговле (15\%), в строительстве (14\%), на предприятиях транспорта и связи (12\%). Доля респондентов, работающих на предприятиях с численностью персонала до 100 чел., составила $60 \%$, на средних предприятиях (от 100 до 500 чел.) - 27\%, на крупных предприятиях (более 500 человек) - 13\%. Среди респондентов $45 \%$ женщин и $55 \%$ мужчин. Средний возраст опрошенных специалистов - 38 лет, средний стаж работы по специальности - 10 лет, средний стаж работы в организации - 6 лет.

Статья организована следующим образом. Вначале мы характеризуем условия работы российских профессионалов, базируясь на традиционных показателях, используемых в диагностике качества трудовой жизни. Далее приводим обоснование системы индикаторов, позволяющих оценить степень психосоциальных рисков, и рассматриваем их соотношение в плане значимости для работников.

\section{Качество трудовой жизни: характеристики рабочих мест и удовлетворенность работой}

Анализ организационных условий, определяющих качество трудовой жизни, опирается на объективные параметры и субъективные оценки трудовой ситуации. Объективные параметры (тип трудового контракта, продолжительность рабочего времени, порядок и формы оплаты труда, наличие социальных гарантий и льгот) предполагают соотнесение фактического положения дел с существующими стандартами, которые во многом заданы представлениями о социальной защищенности в сфере труда, присущими государству благосостояния в индустриальную эпоху.

Один из основных квалифицирующих признаков защищенного труда - постоянный (бессрочный) трудовой договор. В нашей выборке данный тип контракта является преобладающим: на условиях бессрочного договора заняты 77 \% респондентов, еще около $17 \%$ имеют контракты на фиксированный, чаще всего 3-5-летний срок (см. табл. 1). Длительные контракты помимо относительной надежности рабочего места обеспечивают сотрудникам базовые, законодательно установленные гарантии и компенсации (ежегодный оплачиваемый отпуск и пр.).

Важным источником социальных благ являются также льготы и выплаты социального характера, предоставляемые компанией за счет собственных средств. О наличии каких-либо дополнительных социальных услуг в своей организации 
сообщили $53 \%$ респондентов. Чаще всего встречается оплата мобильной связи и корпоративное медицинское страхование (25\% и $22 \%$ ), компенсация транспортных расходов (15\%) и обеспечение питанием на работе (11\%). Объем услуг варьируется в зависимости от размера компании: чем больше компания, тем "толще" социальный пакет.

Защищенность дохода определяется размером, формой и порядком оплаты труда. Ключевым индикатором выступает фактический размер заработка: в структуре трудовых предпочтений россиян этот параметр работы лидирует с двойным отрывом от других характеристик [Козина, 2020]. По нашему массиву среднемесячный размер трудового дохода соответствует аналогичному показателю по РФ за тот же период ${ }^{3}$. По профессиональным группам наблюдаются существенные различия: выше всех оплачивается труд IT-специалистов, ниже всех - труд условных «бухгалтеров". Другим важным индикатором защищенности в оценке оплаты труда является устойчивость трудового дохода, которая характеризуется соотношением постоянной (гарантированной, базовой) и переменной (компенсационные и стимулирующие выплаты) части в структуре заработной платы. Здесь данные опроса показывают вполне благополучную картину: доля переменной части не превышает $12 \%-18 \%$. Негативным моментом можно считать частичное сохранение практик теневых выплат (за последние шесть месяцев, предшествующих опросу, примерно каждый пятый получал часть зарплаты "в конверте»), однако на долю “серой" части заработка приходится в среднем только $6 \%$.

Рабочее время большинства опрошенных специалистов всех категорий укладывается во временной интервал 40-42 часов в неделю. Доля занятых с чрезмерной продолжительностью (более 45 часов) составляет 19\%, и это практически единственный показатель, по которому наблюдаются значимые гендерные различия: мужчины перерабатывают чаще, чем женщины (23\% против 15 \%). Однако следует учитывать, что под рабочим временем подразумевается время пребывания на рабочем месте. Чтобы оценить совокупный объем сверхнормативной занятости, необходимо привлечь также информацию о работе, перетекающей за пределы цехов и офисов, и об этом речь пойдет дальше.

Субъективное восприятие трудовой ситуации традиционно измеряется через показатель удовлетворенности работой и ее отдельными аспектами. По сумме ответов "удовлетворен" и "вполне удовлетворен" доля позитивно оценивающих разные стороны своей работы колеблется от $55 \%$ до $83 \%$. Наибольшую степень удовлетворенности опрошенные специалисты демонстрируют в отношении содержания своего труда (83\%) и этим существенно отличаются от работающих граждан в целом, среди которых соответствующий показатель составляет 70\%, занимая только пятое место среди оцениваемых параметров работы [Козина, 2020]. Примерно так же высоко оцениваются сложившиеся межличностные отношения на работе. Далее по убывающей следуют такие базовые характеристики трудовой ситуации, как режим работы, комфортность и надежность рабочего места. Этими аспектами работы удовлетворены $72 \%-77 \%$ респондентов. Относительно невысоко оцениваются те аспекты трудовой ситуации, которые можно объединить ка-

\footnotetext{
3 Рассчитано по: Росстат. Средняя начисленная заработная плата работников по категориям персонала и видам экономической деятельности. URL: https://rosstat.gov.ru/compendium/document/60671 (дата обращения: 20.06.2021).
} 
тегорией "возможности" (проявления самостоятельности и инициативы, обучения и повышения квалификации, профессионального роста). В наименьшей степени респонденты удовлетворены зарплатой и трудовой нагрузкой (объемом и темпом работы). Последнее, соответственно ограничивает возможность иметь достаточно свободного времени для жизни и семьи - это самый низкий показатель.

Можно было бы оптимистично утверждать, что образованные и квалифицированные работники, каковыми являются наши респонденты, обладают рабочими местами достаточно высокого качества, близкого к одобряемому стандарту, а также в целом довольны своей работой. Между тем данные опроса фиксируют наличие серьезных проблем, связанных с психологической безопасностью. Каждый третий опрошенный специалист - вне зависимости от профессии - признает, что его работа сопряжена с большим психическим напряжением, а каждый второй отмечает усиление психологической нагрузки на работе за последние два года. Это свидетельствует о том, что ряд организационных условий содержит достаточно высокие психосоциальные риски для сотрудников.

Таблица 1. Характеристики рабочих мест и удовлетворенность работой

\begin{tabular}{|c|c|c|c|c|c|}
\hline & \begin{tabular}{|c|} 
В целом \\
по выборке \\
\end{tabular} & ИTP & Бухгалтеры & Менеджеры & \begin{tabular}{|c|} 
IT- \\
специалисты
\end{tabular} \\
\hline \multicolumn{6}{|l|}{ Тип оформления трудовых отношений } \\
\hline $\begin{array}{l}\text { Заняты на условиях бессрочного } \\
\text { договора, \% }\end{array}$ & 77,1 & 79,0 & 73,0 & 75,6 & 79,0 \\
\hline $\begin{array}{l}\text { Заняты на условиях временного } \\
\text { контракта, \% }\end{array}$ & 16,8 & 17,0 & 18,5 & 16,8 & 13,3 \\
\hline $\begin{array}{l}\text { Заняты на других условиях } \\
\text { (гражданско-правовой договор, } \\
\text { договор с индивидуальным } \\
\text { предпринимателем, по устной } \\
\text { договоренности), \% }\end{array}$ & 6,1 & 4,0 & 8,5 & 7,6 & 7,7 \\
\hline \multicolumn{6}{|c|}{ Рабочее время (за последнюю полную рабочую неделю) } \\
\hline До 40 часов в неделю, \% & 70,5 & 71,2 & 71,1 & 67,6 & 70,9 \\
\hline 41-45 часов в неделю, \% & 10,5 & 9,4 & 10,3 & 10,6 & 14,2 \\
\hline Более 45 часов в неделю, \% & 19,0 & 19,4 & 18,6 & 21,8 & 14,9 \\
\hline \multicolumn{6}{|c|}{ Оплата труда (за последние 6 месяцев) } \\
\hline $\begin{array}{l}\text { Доля тех, кто целиком или } \\
\text { частично получал зарплату “в } \\
\text { конверте», \% }\end{array}$ & 18 & 19 & 17 & 14 & 21 \\
\hline Переменная часть зарплаты, \% & 16 & 18 & 14 & 16 & 12 \\
\hline Среднемесячный заработок, руб. & 34694 & 36143 & 29892 & 32259 & 40895 \\
\hline \multicolumn{6}{|c|}{ Удовлетворенность работой (среднее по пятибалльной шкале) } \\
\hline Содержание работы & 4,13 & 4,12 & 4,09 & 4,09 & 4,30 \\
\hline $\begin{array}{l}\text { Отношения с коллегами, } \\
\text { руководителем }\end{array}$ & 4,09 & 4,10 & 4,09 & 4,01 & 4,10 \\
\hline Режим работы, рабочий график & 4,06 & 4,01 & 4,17 & 4,01 & 4,13 \\
\hline $\begin{array}{l}\text { Условия труда, комфортность ра- } \\
\text { бочего места }\end{array}$ & 4,03 & 3,97 & 4,11 & 3,99 & 4,14 \\
\hline Надежность рабочего места & 3,97 & 3,98 & 4,00 & 3,95 & 3,89 \\
\hline
\end{tabular}




\begin{tabular}{|l|c|c|c|c|c|}
\hline & $\begin{array}{c}\text { В целом } \\
\text { по выборке }\end{array}$ & итР & Бухгалтеры & Менеджеры & $\begin{array}{c}\text { IT- } \\
\text { специалисты }\end{array}$ \\
\hline $\begin{array}{l}\text { Возможности проявить самостоя- } \\
\text { тельность, инициативу }\end{array}$ & 3,82 & 3,84 & 3,83 & 3,80 & 3,75 \\
\hline $\begin{array}{l}\text { Возможности обучения, профес- } \\
\text { сионального развития }\end{array}$ & 3,76 & 3,77 & 3,77 & 3,68 & 3,82 \\
\hline Объем и темп работы & 3,75 & 3,76 & 3,75 & 3,71 & 3,73 \\
\hline Уровень зарплаты & 3,68 & 3,70 & 3,74 & 3,57 & 3,66 \\
\hline $\begin{array}{l}\text { Возможность иметь достаточно } \\
\text { свободного времени }\end{array}$ & 3,62 & 3,60 & 3,66 & 3,61 & 3,60 \\
\hline
\end{tabular}

\section{Оценка психосоциальных рисков организационной среды}

Основные подходы к оценке психосоциальных рисков определяются спецификой тех предметных областей, в рамках которых проводятся исследования. В психологии труда акцент чаще делается на индивидуальных ресурсах и психологических особенностях реагирования на неблагоприятные факторы организационной среды. Социологи фокусируются на анализе непосредственно средовых условий (выделении и ранжировании потенциально небезопасных для психологического здоровья факторов), рассматривая их воздействие на работников сквозь призму не индивидуальных, а организационных ресурсов. Несмотря на различие подходов, в настоящее время в экспертном сообществе существует относительное единство мнений о характере психосоциальных рисков, хотя исследователи сходятся в том, что конкретное наполнение этой категории нельзя считать окончательным, поскольку новые формы труда и изменения производственной среды порождают все новые опасные факторы.

Анализ состояния исследований в данной области позволяет выделить пять основных групп организационных факторов, представленных в большинстве предлагаемых измерительных схем: стабильность трудовой ситуации, интенсивность труда, автономия на рабочем месте, ценностный баланс, взаимоотношения на работе. В ряде случаев, если это обусловлено спецификой профессии, принято выделять дополнительные группы факторов, например, характеризующих физические аспекты безопасности или эмоциональные риски, в значительной степени свойственные профессиям, предполагающим постоянное общение с людьми [Muntaner et al., 2006]. В данной работе мы добавляем факторы, связанные с содержанием труда, в частности, со степенью рутинизации производственных функций, монотонностью, повторяющимися действиями на работе, что, хотя и не является в прямом смысле характеристикой организационной среды, применительно к работникам интеллектуального труда нередко выделяется в качестве отдельного фактора риска.

Стабильность трудовой ситуации считается одним из главных условий обеспечения психологической безопасности сотрудников. Источником риска здесь выступает состояние неопределенности, неуверенности в будущем (угроза потери работы). Помимо отсутствия гарантий занятости это состояние может быть вызвано частыми изменениями трудовых обязанностей и условий труда, что вынуждает сотрудников постоянно адаптироваться к новым "правилам игры", порождая ощущение непредсказуемого, неконтролируемого развития событий 
[Kossek, Kalliath, Kalliath, 2012]. В определении степени психосоциальных рисков показатель изменчивости рабочей ситуации чрезвычайно важен - свидетельством этого являются результаты исследований в компании Франс Телеком, где частые организационные изменения были признаны основной причиной стресса, повлекшего за собой серию самоубийств сотрудников [Servant, 2013].

Интенсивность труда в качестве фактора риска традиционно трактуется как требование рабочей среды, превышающее ресурсы работника. Здесь содержится прямая отсылка к трудам по оценке стрессовых условий на работе [Karasek, 1979; Siegrist et al., 2004]. Интенсивность труда измеряется с помощью как количественных (продолжительность рабочего времени), так и качественных показателей, таких как субъективная оценка объемов, сроков и темпов труда [Gollac, Bodier, 2011; Barney, Elias, 2010; Giauque, Anderfuhren-Biget, Varone, 2018]. В данной группе индикаторов мы аккумулируем переменные, фиксирующие чувство усталости, эмоционального напряжения, связанного с работой, оценку реалистичности дедлайнов, наличие сверхурочной работы и степень влияния трудовой нагрузки на личную жизнь и семейные обязанности.

Автономия, или "свобода принятия решений" - в терминах Р. Карасека, обычно рассматривается в связке с интенсивностью труда. Предполагается, что психологические риски возникают при высокой интенсивности и низкой степени автономии, в то время как возможности контроля условий своей работы могут частично компенсировать повышенную трудовую нагрузку [Karasek, 1979]. В качестве индикаторов здесь выступают оценка степени самостоятельности в реализации производственных заданий, контроля со стороны руководства за их выполнением, включенность в процесс принятия решений относительно организации рабочего процесса, своего и на уровне подразделения.

Взаимоотношения на работе - параметр, который традиционно присутствует в оценке условий трудовой жизни. Психосоциальные риски в данном случае детерминированы процессами взаимодействия и общения на работе и определяются степенью поддержки со стороны коллег в профессиональном и в эмоциональном плане, стилем руководства и пр. [Saint-Hilaire, 2008; Gollac, Bodier, 2011]. При идентификации состояния межличностных отношений мы акцентировали внимание на взаимодействии в системе "руководитель - подчиненный" как на самом уязвимом аспекте внутриорганизационной коммуникации [Балабанова, Боровик, Деминская, 2018]. В число индикаторов вошли оценки справедливости в распределении заданий, поощрениях и наказаниях, частота проявления деструктивного поведения со стороны руководства (игнорирование достижений, нарушение обещаний, грубость, публичное унижение и пр.).

Ценностный баланс является относительно новой категорией в диагностике рабочей ситуации, отражающей смысл и моральные основания труда. С позиции психосоциальных рисков фиксируется наличие противоречий между требованиями организационной среды (административные указания, корпоративные ценности и пр.) и личными профессиональными и нравственными нормами работника [Vézina et al., 2008; Gollac, Bodier, 2011]. К примеру, руководство загружает сотрудников бесполезной в глазах ее носителей работой или в целях экономии намеренно снижает качество продукта/услуги, тем самым вынуждая 
делать менее качественную работу. Маркерами ценностного баланса выступает оценка социальной значимости собственного труда, степень использования трудового потенциала (соответствие производственных задач уровню знаний и квалификации, частота выполнения работы, не входящей в прямые должностные обязанности), а также степень лояльности организации и приверженности корпоративным ценностям.

Содержание труда оценивается на основе соотношения в работе "творчества" и "рутины". Рутинная работа далеко не всегда повышает вероятность возникновения негативных психологических состояний, однако считается, что для профессионалов, как правило, воспринимающих свою профессию в качестве экспертной и творческой, длительное выполнение однообразной работы способно вызывать эффект ролевой недогрузки, что грозит быстрым эмоциональным выгоранием и стрессом [Karasek et al., 1981]. В оценке факторов риска, связанных с содержанием труда, индикаторами являются интерес к работе, оценка его творческой составляющей и степени рутинизации производственных функций.

Для комплексного представления ситуации индикаторы с высоким уровнем внутренней согласованности по каждой группе факторов были сведены в индексы путем расчета средних значений. Всего в анализ вошли 32 переменные, характеризующие субъективное восприятие различных аспектов работы (выражение степени согласия с утверждениями или оценка частоты совершения определенных действий). Число исходных переменных, входящих в индексы, варьировалось от 4 (при измерении стабильности и ценностного баланса) до 7 (при измерении интенсивности труда). Шкалы были нормированы, каждая из них изменялась от -1 до 1, где максимально отрицательное значение фиксировало высокую степень рисков, а максимально положительное значение - их отсутствие.

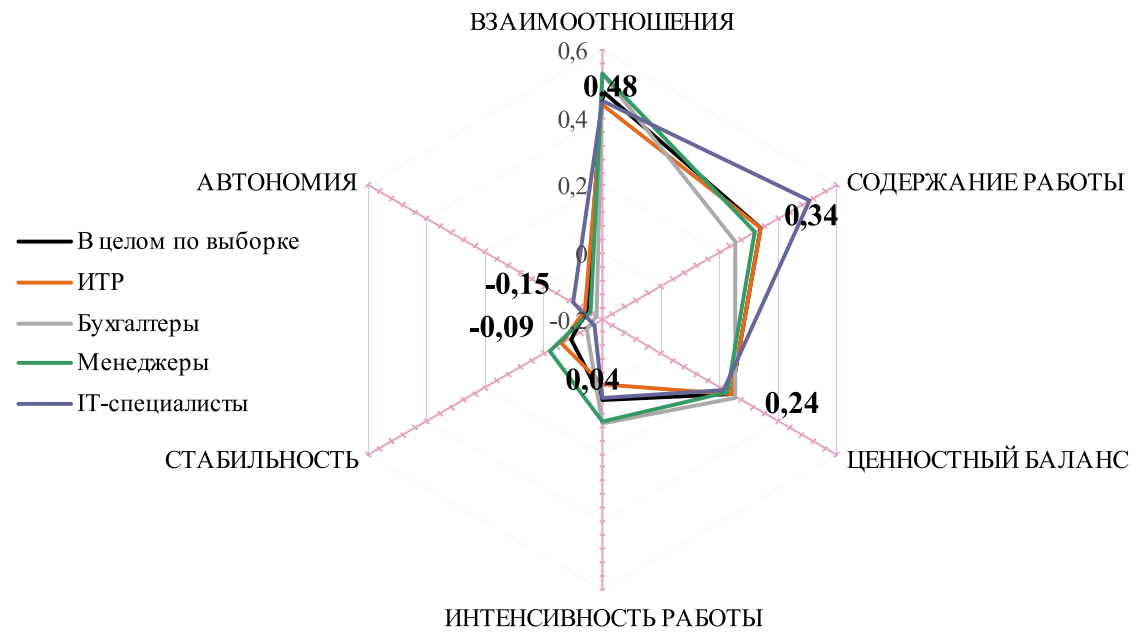

Рис. 1. Профиль психосоциальных рисков

Результаты измерения, представленные на рисунке 1, демонстрируют две выраженные группы параметров. Наименьшие риски содержат социальные аспекты 
работы, такие как взаимоотношения на работе (степень риска здесь минимальна), содержание труда и ценностный баланс. В то же время характеристики трудовой ситуации, напрямую связанные с организацией и управлением трудовыми процессами: автономия, стабильность (индексы принимают отрицательное значение) и интенсивность труда (значение индекса близко к критическому),-требуют более пристального внимания.

По обобщенным характеристикам, которые представляют собой индексы, существенных различий по профессиям не наблюдается. Исключение составляет группа IT-специалистов, в которой значение индекса содержания труда наиболее высокое, что объясняется спецификой работы, где творческая составляющая легко реализуется. По другим параметрам результаты схожи, что говорит о консистентности данных и позволяет анализировать картину соотношения имеющихся рисков и их значимости в целом для всех респондентов.

\section{Организационные условия как требования и ресурсы}

Корреляционный анализ демонстрирует слабую положительную связь степени выраженности психосоциальных рисков с соответствующими параметрами удовлетворенности работой: значения коэффициентов находятся в интервале от 0,2 до 0,4 (при значимости 0,01). С одной стороны, такая рассогласованность в оценках может объясняться сложной природой самого концепта удовлетворенности работой, отражающего как степень субъективного благополучия, так и уровень притязаний, который может быть обусловлен различными причинами, что выводит анализ за пределы сферы действий организации. С другой стороны, это может определяться спецификой взаимодействия организации и работника. Поскольку наши данные не позволяют судить о степени влияния внешних факторов на восприятие работниками тех или иных психосоциальных рисков, мы рассматриваем их как внутрисистемные, обусловленные организацией рабочих процессов и обстановкой на работе. В качестве аналитической рамки выступает модель требований-ресурсов (JD-R model) A. Бэккера и Е. Демерути, согласно которой предполагается, что одни характеристики рабочего процесса могут выступать как повышенные организационные требования, другие - как ресурсы, предоставляемые организацией и позволяющие противостоять этим требованиям, то есть играть роль “буфера" для преодоления воздействия неблагоприятных факторов. Ключевая идея авторов состоит в том, что даже при высоких требованиях рабочей среды (физических, ментальных, эмоциональных и пр.) необязательно будет наблюдаться негативный эффект. Если доля значимых организационных ресурсов высока, то влияние негативных факторов будет снижено, к таким ресурсам авторы относят: автономию, социальную поддержку, обратную связь и др. [Bakker, Demerouti, 2007]. В то же время модель "работает" со спецификой профессии, предполагая, что в разных случаях одни и те же характеристики могут выступать и как требования, и как ресурсы. Например, сложные задачи могут профессионально мотивировать одних, но играть роль повышенных требований для других [Bakker, Demerouti, 2017]. Добавим, что это же будет верно для различных социокультурных контекстов: в зависимости от особенностей трудовой культуры и ценностных приоритетов одни и те же характеристики работы будут выполнять разную роль. 
В рамках данной объяснительной модели и в соответствии с полученными результатами взаимоотношения на работе, содержание труда и ценностный баланс выступают в качестве ресурсов для ответа на требования организационной среды, связанные с низкой автономией, повышенной интенсивностью труда и нестабильностью рабочей ситуации. Однако для того, чтобы более отчетливо представить общую ситуацию, важно установить, какие именно параметры рабочей среды (компоненты индексов) формируют зону риска, а какие выступают в качестве социальных амортизаторов.

\section{Неопределенность, несвобода и перегрузки как факторы риска}

Низкое значение индекса стабильности определяется в основном за счет того, что трудовые обязанности подвержены частым изменениям. Две трети респондентов отмечают, что в их работе постоянно появляются новые требования. По имеющимся данным сложно судить о степени глубины и значимости для них этих изменений, но понятно, что частые порывы руководства разнообразить деятельность и менять подходы повышают градус напряжения и раздражения, заставляя сотрудников быть постоянно в напряжении, в готовности к очередным поправкам, новым правилам и инструкциям. Очевидно, что трудовая жизнь в режиме частых изменений становится приметой времени, и здесь важно, насколько безболезненны эти процессы для сотрудников. Риск возникновения негативных психологических состояний повышается, если работники отстранены от участия в принятии решений и изменения не сопровождаются объяснениями и предварительным информированием. Ключевым индикатором положения дел здесь был вопрос “Обсуждались ли предварительно изменения, нововведения, касающиеся вашей работы, подразделения, в котором вы работаете?", на который только треть респондентов ответили утвердительно. Этот риск стоит воспринимать как реальный, поскольку практики коллективного обсуждения и учета мнения сотрудников, видимо, не являются сильной стороной менеджмента российских компаний.

Относительно стабильности рабочего места (второй составляющей данного индекса) ситуация не выглядит критичной: доля пессимистически настроенных работников, ощущающих реальную угрозу потери работы, составила $18 \%$. Напомним, что большинство рабочих мест защищено постоянным контрактом. Это, конечно, не дает гарантии, что работодатель при необходимости не найдет обходные пути для увольнения сотрудника, но тем не менее позволяет чувствовать себя более уверенно в отношении перспектив сохранения своей рабочей позиции.

Значение индекса по оси интенсивности труда $(0,04)$ хотя и не принимает отрицательного значения, но довольно близко к нему. В данный индекс заложено субъективное восприятие соотношения имеющегося времени и сложности, объема работы. Необходимость выполнять большой объем работы в условиях жестких дедлайнов повышает риск возникновения стресса и снижения общей эффективности работы, то есть серьезный дисбаланс этих параметров приводит к негативным последствиям как для работника, так и для организации. Основной вклад в низкое значение индекса вносит распространенность практик перера- 
боток. Две трети респондентов отметили, что вынуждены трудиться сверхурочно (задерживаться на работе сверх положенного времени, работать в выходные дни, брать работу на дом). Сверхурочная работа не всегда инициируется непосредственным распоряжением начальства и может быть инициативой самих работников (среди респондентов таких примерно треть), однако это означает, что объем и сложность работы велики и работник не справляется с ней в фиксированное рабочее время. Почти половина (45\%) специалистов признают, что вынуждены участвовать в "непрекращающейся гонке со временем". Это очевидным образом негативно отражается на балансе жизни и работы. Примерно треть опрошенных (37\%) утверждают, что работа не оставляет времени на личные интересы, каждому пятому работа не позволяет уделять достаточно внимания своей семье. Обратная ситуация (когда личные проблемы мешают работе) отмечается гораздо реже, в 12\%-17\% случаев. Данные опроса фиксируют также тенденции роста интенсивности труда - по меньшей мере в глазах сотрудников: среди значимых изменений в работе, происходящих за последние два года, $60 \%$ респондентов отметили повышение объемов и сложности работы. Следствием повышенной нагрузки является чувство постоянной усталости, которым, по признанию каждого второго, сопровождается их работа, а каждый четвертый в конце рабочего дня ощущает себя "полностью обессиленным". Если такая значительная часть сотрудников заявляет о существенной перегрузке, это должно стать для менеджмента компаний сигналом к пересмотру рабочих процессов и более внимательному анализу ситуации.

Важным элементом диагностики трудовой жизни, приобретающим в контексте психосоциальных рисков дополнительное значение фактора, способного усилить или частично компенсировать негативное действие других организационных факторов, является категория автономии. В нашем случае данный индекс принимает максимально отрицательное значение, то есть автономия не только не обладает силой "буфера", но и указывает на наличие серьезных рисков. Наибольший вклад в низкое значение индекса вносят ответы на вопросы, связанные с возможностями участия в принятии решений. Более 70 \% опрошенных отметили, что процесс разработки и принятия решений осуществляется руководителем единолично, максимум в этом участвует узкий круг подчиненных. Только около трети сотрудников заявляют о возможности высказывать предложения и проявлять инициативу относительно работы подразделения и своей собственной работы. В отношении оценки самостоятельности на рабочем месте складывается неоднозначная картина. Половина респондентов согласились с утверждением "Мне предоставлена значительная свобода в определении того, как выполнять свою работу". Одновременно $60 \%$ опрошенных указали на то, что выполнение работы сопровождается постоянным строгим контролем, то есть предоставляемая свобода может быть скорее формальной, реальная автономия в выполнении задач будет ниже заявленной. Более благоприятная ситуация фиксируется лишь в группе IT-специалистов: 62 \% из них считают себя вполне самостоятельными в определении того, как выполнять свою работу, а о наличии постоянного контроля они говорят в два раза реже остальных респондентов (33\%). 


\section{Межличностные отношения и содержание труда как социальные амортизаторы рисков}

Наиболее "сильным" ресурсом выступают отношения на работе. Значение индекса указывает на то, что риски относительно межличностной коммуникации минимальны. Благоприятная атмосфера в коллективе традиционно трактуется как одно из основных условий психологической безопасности сотрудников и обеспечивается в большей степени поддержкой со стороны коллег, в меньшей степени, но все же значительно, со стороны руководства. Так, $60 \%$ респондентов выразили согласие с суждением «Если у кого-то что-то не выходит на работе, ему всегда приходят на помощь товарищи, дадут совет, объяснят», и около 50 \% отметили поддержку со стороны руководителя. Случаи проявления грубости, несправедливого отношения, открытой неприязни, обвинений в некомпетентности зафиксированы только у $6 \%-14 \%$ опрошенных. Важно уточнить, что здесь оценивались непосредственные руководители, с которыми чаще устанавливаются более равные и во многом персонифицированные отношения.

Другим важным ресурсом является содержательно интересная работа. Содержание труда для высококвалифицированных специалистов имеет особую значимость: эта основа их профессиональной идентичности. Несмотря на достаточно высокую степень рутинизации трудовых функций (43\% респондентов охарактеризовали свою работу как состоящую из “однообразных, повторяющихся заданий»), большинство опрошенных находят свою работу интересной (84\%) и творческой (64\%), то есть само по себе наличие рутины не может однозначно свидетельствовать о серьезных рисках.

В оценке параметров работы, входящих в индекс "ценностный баланс", собственная работа также предстает как социально значимая: $62 \%$ специалистов высоко оценили свой труд, согласившись с суждением "Я горжусь той работой, которую я делаю". Такое восприятие работы создает надежные предпосылки для идентификации работника с организацией, в которой она выполняется. Маркером высокой степени организационной лояльности является субъективное восприятие сопричастности компании, ее успехам и проблемам: больше половины респондентов (55\%) согласились с утверждением «Я воспринимаю проблемы компании, как свои собственные", то есть на ценностном уровне сотрудники принимают стратегию и культуру компании.

Результаты исследования дают основания полагать, что в создании сбалансированной рабочей среды в российских организациях важную роль играют социальные аспекты работы. Это позволяет "буферизовать" негативно выраженные характеристики и, как следствие, формирует достаточно высокий уровень субъективного благополучия. В то же время ряд условий, связанных с низким уровнем автономии на рабочих местах, повышенной трудовой нагрузкой, ограниченными возможностями участия в принятии решений, отсутствием обратной связи при введении новых организационных правил и пр., потенциально приводит к снижению качества жизни сотрудников и эффективности их работы. Эти аспекты трудовой ситуации нуждаются в более пристальном внимании, поскольку оказываются основным источником организационных требований, для осуществления которых работники могут не найти необходимых ресурсов. 


\section{Заключение}

Распространение работы, сопряженной с высокой психологической нагрузкой, признается сегодня одной из ключевых проблем сферы труда, что в числе прочего влечет за собой пересмотр тех показателей, по которым характеризуется производственная ситуация. Традиционных методик измерения качества трудовой жизни может быть недостаточно для комплексной диагностики трудовой ситуации, и концептуальное включение в них оценки психосоциальных рисков на работе становится насущной необходимостью.

Примеры зарубежных стран демонстрируют важность своевременной диагностики и корректировки "красных зон" для снижения уровня психосоциальных рисков, которые могут "взорваться" в самый неподходящий момент. Физическое и психологическое здоровье перестает быть предметом исключительно индивидуальной заботы и, поскольку подвергается значительному влиянию со стороны рабочего пространства, переходит в обязанности работодателя. В ряде стран требования к работодателям проводить оценку психосоциальных рисков закреплены законодательно [ILO, 2016]. Инструменты диагностики рисков разрабатываются как на международном уровне [EU-OSHA, 2019], так и в рамках национальных программ, например в Великобритании [HSE, 2007]. Кроме опросных методик, данные программы предполагают использование объективной информации о состоянии сотрудников (отсутствие на работе по причине болезни, текучесть персонала и пр.), а также содержат перечень рекомендуемых мер для корректировки организационной ситуации в целом и адресной помощи сотрудникам [Сережкина, 2019].

В контексте обсуждения методик измерения психосоциальных рисков открытым остается вопрос об их оптимальном уровне и допустимых границах. Реакции на неблагоприятные факторы организационной среды обусловлены сложным переплетением социальных норм, трудовой этики, спецификой представлений об успехе, работе и отдыхе. К примеру, если практики переработок нормализуются и воспринимаются как часть трудовых обязанностей, работники будут более адаптивны к неблагоприятным условиям рабочей среды, поскольку длительное время эти условия существуют для них как близкие к норме [Козина, Сережкина, 2019]. С точки зрения критически настроенных исследователей, в рамках сложившейся универсалистской традиции игнорируются как специфика социальной среды (профессиональной, социокультурной), так и появление новых общих зон уязвимости работников, требующих специальных методов выявления и мер предупреждения [Buscatto, Loriol, Weller, 2008]. Отсюда следует вывод о необходимости учитывать актуальные средовые характеристики в программах измерения качества трудовой жизни и противодействия профессиональному выгоранию и стрессу. Разделяя эту позицию, мы видим перспективным направлением дальнейшего анализа развитие и уточнение предложенного инструментария с учетом профессиональной и организационной специфики, что позволит получить более объемную картину допустимых границ психосоциальных рисков и возможностей управления ими и при этом сохранить баланс производительности труда и благополучия работников. 


\section{Список литературы (References)}

Абрамов Р.Н., Груздев И. А., Терентьев Е. А. Баланс работы и личной жизни и источники стресса научно-педагогических работников российских исследовательских университетов // Мониторинг общественного мнения: экономические и социальные перемены. 2019. № 3. С. 8-26. https://doi.org/10.14515/monitoring.2019.3.02. Abramov R. N., Gruzdev I. A., Terentiev E. A. (2019) Work-life Balance and Sources of Stress for the Academic Staff in Russian Research Universities. Monitoring of Public Opinion: Economic and Social Changes. No. 3. P. 8-26. https://doi.org/10.14515/ monitoring.2019.3.02. (In Russ.)

Балабанова Е.С. Качество трудовой жизни работников российских бизнесорганизаций: аккумулирование или компенсация неравенств? // XVI Апрельская международная научная конференция по проблемам развития экономики и общества: в 4 кн. / отв. ред.: Е. Г. Ясин. Кн. 1. М. : Издательский дом НИУ ВШЭ, 2016. C. $397-405$.

Balabanova E.S. (2016) The Working Life Quality of Russian Business Organizations Workers: Accumulating or Compensating for Inequalities? In: E. G. Yasin (ed.) XVI April International Scientific Conference on the Problems of Economic and Social Development. Vol. 1. Moscow: HSE Publishing House. P. 397-405. (In Russ.)

Балабанова Е.С., Боровик М. Э., Деминская В. Э. “Враждебное» поведение руководителя: проявления, предпосылки и последствия // Российский журнал менеджмента. 2018. T. 16. № 3. С. 309-336. https://doi.org/10.21638/spbu18.2018.301. Balabanova E.S., Borovik M.E., Deminskaya V.E. (2018) Abusive Supervision: Manifestations, Antecedents, and Consequences. Russian Management Journal. Vol. 16. No. 3. P. 309-336. https://doi.org/10.21638/spbu18.2018.301. (In Russ.)

Давыдова И. А., Козьмина Я.Я. Профессиональный стресс и удовлетворенность работой преподавателей российских вузов // Вопросы образования. 2014. № 4. C. 169-183. https://doi.org/10.17323/1814-9545-2014-4-169-183.

Davydova I., Kozmina Y. (2014) Occupational Stress and Job Satisfaction among Professors of Russian Higher Educational Institutions. Voprosy obrazovaniya/ Educational Studies Moscow. No. 4. P. 169-183. https://doi.org/10.17323/18149545-2014-4-169-183. (In Russ.)

Качановецкая Н.И. Стресс-факторы производственной среды в деятельности банковских служащих // Вестник Российского университета дружбы народов. Серия: Экология и безопасность жизнедеятельности. 2015. № 2. С. 94-99.

Kachanovetskaya N. I. (2015) Stress Factors of the Production Environment in Activity of Bank Employees. RUDN Journal of Ecology and Life Safety. No. 2. P. 94-99. (In Russ.)

Козина И. М., Сережкина Е.В. Производственные факторы стресса в работе российских и французских IT-специалистов // Социологические исследования. 2019. № 5. C. 26-35. https://doi.org/10.31857/S013216250004950-8.

Kozina I. M., Serezhkina E. V. (2019) Stressful Characteristics of Work of Russian and French Software Developers. Sociological Studies. No. 5. P. 26-35. https://doi.org/ 10.31857/S013216250004950-8. (In Russ.) 
Козина И. М. Человек на работе: мир труда в оценках россиян // Социодиггер. 2020. Том 1. Вып. 1: Труд и занятость. С. 5-15.

Kozina I. M. (2020) A Person at Work: World of Work According to Russians. Sociodigger. Vol. 1. No.1. P. 5-15. (In Russ.)

Константиновский Д. Л., Пинская М.А., Звягинцев Р.С. Профессиональное самочувствие учителей: от энтузиазма до выгорания // Социологические исследования. 2019. № 5. C. 14-25. https://doi.org/10.31857/S013216250004949-6.

Konstantinovskiy D. L., Pinskaya M. A., Zviagintsev R. S. (2019) Professional Health of Teachers: From Enthusiasm to Burnout. Sociological Studies. No 5. P. 14-25. https:// doi.org/10.31857/S013216250004949-6. (In Russ.)

Смолева Е. О. Социальная адаптация, социальный капитал и здоровье населения Вологодской области // Мониторинг общественного мнения: экономические и социальные перемены. 2020. № 4. С. 136-161. https://doi.org/10.14515/ monitoring.2020.4.983.

Smoleva E. O. (2020) Social Adaptation, Social Capital and Population Health in the Vologda region. Monitoring of Public Opinion: Economic and Social Changes. No. 4. P. 136-161. https://doi.org/10.14515/monitoring.2020.4.983. (In Russ.)

Сережкина Е. В. Управление стрессом на рабочем месте: организационный подход // Российский журнал менеджмента. 2019. T. 17. № 2. С. 233-250. https:// doi.org/10.21638/spbu18.2019.205.

Serezhkina E. V. (2019) Managing Workplace Stress: Organizational Approach. Russian Management Journal. Vol. 17. No. 2. P. 233-250. https://doi.org/10.21638/ spbu18.2019.205. (In Russ.)

Соболева И., Чадова Т. Социально-экономическая защищенность населения: ключевые аспекты и тенденции изменения // Вестник Института экономики Российской академии наук. 2013. № 6. С. 70-91.

Soboleva I., Chadova T. (2013) Socio-economic Security of the Population: Key Aspects and Trends of Change. The Bulletin of the Institute of Economics of the Russian Academy of Sciences. No. 6. P. 70-91. (In Russ.)

Тихонова Н.Е. Российские профессионалы: специфика рабочих мест и человеческого потенциала // Социологические исследования. 2020. № 10. С. 71-83. https://doi.org/10.31857/S013216250010300-3.

Tikhonova N. Ye. (2020) Russian Professionals: Specifics of Jobs and of Human Potential. Sociological Studies. No. 10. P. 71-83. https://doi.org/10.31857/ S013216250010300-3. (In Russ.)

Bakker A., Demerouti E. (2007) The Job Demands-Resources Model: State of the Art. Journal of Managerial Psychology. No. 3. P. 309-328.

Bakker A., Demerouti E. (2017) Job Demands - Resources Theory: Taking Stock and Looking Forward. Journal of Occupational Health Psychology. No. 3. P. 273-285.

Barney C., Elias S. (2010) Flex-Time as a Moderator of the Job Stress-Work Motivation Relationship. A Three-Nation Investigation. Personnel Review. Vol. 39. No. 4. P. 487-502. 
Beque M., Mauroux A., Baradji E., Dennevault C. (2017) Quelles sont les évolutions récentes des conditions de travail et des risques psychosociaux? DARES Résultats. $\mathrm{N}^{\circ} 082$.

Burr H., Berthelsen H., Moncada S., Nübling M., Dupret E., Demiral Y., Oudyk J., Kristensen T., Lorens C., Navarro A., Lincke H-J., Bocéréan C., Sahan C, Smith P., Pohrt A. (2019) The Third Version of the Copenhagen Psychosocial Questionnaire. Safety and Health at Work. Vol. 10. No. 4. P. 482-503.

Buscatto M., Loriol M., Weller J.-M. (eds.) (2008) Au-delà du stress au travail, Une sociologie des agents publics au contact des usagers. Toulouse: Erès.

EU-OSHA (2019). Third European Survey of Enterprises on New and Emerging Risks (ESENER 3). European Agency for Safety and Health at Work: Bilbao.

Giauque D., Anderfuhren-Biget S., Varone F. (2019) Stress and Turnover Intents in International Organizations: Social Support and Work — Life Balance as Resources. The International Journal of Human Resource Management. Vol. 30. No. 5. P. 879-901.

Gogoleva A., Sorokin P., Efendiev A. (2017) Research Into Quality of Work Life in Organizational Studies: Problems and Perspectives. Society and Economy. Vol.39. No. 4. P. $597-616$.

Gollac M., Bodier M. (2011) Mesurer les facteurs psychosociaux de risque au travail pour les maîtriser: Rapport du Collège d'expertise sur le suivi des risques psychosociaux au travail. Ministère du Travail, de I'Emploi et de l'Insertion. Avril. URL: http:// travail-emploi.gouv.fr/IMG/pdf/rapport_SRPST_definitif_rectifie_11_05_10.pdf (accessed: 12.02.2021).

HSE: Health and Safety Executive. (2007) Managing the Causes of Work-related Stress. A Step-by-step Approach Using the Management Standards. URL: https:// safetyresourcesblog.files.wordpress.com/2014/10/managing-the-causes-of-workrelated-stress-a-step-by-step-approach-using-management-standards.pdf (accessed: 04.04.2021)

ILO (2012) Decent Work Indicators: Concepts and Definitions. ILO manual. First ed. Geneva: International Labour Office.

ILO (2016) Workplace Stress: A Collective Challenge. Geneva: International Labour Office.

Karasek R. (1979) Job Demands, Job Decision Latitude and Mental Strain: Implications for Job Redesign. Administrative Science Quarterly. No. 24. P. 285-308.

Karasek R., Baker D., Marxer F., Ahlbom A., Theorell T. (1981) Job Decision Latitude, Job Demands and Cardiovascular Disease: Prospective Study of Swedish Men. American Journal of Public Health. Vol. 71. P. 694-705.

Kossek E., Kalliath T., Kalliath P. (2012) Achieving Employee Wellbeing in a Changing Work Environment: an Expert Commentary on Current Scholarship. International Journal of Manpower. Vol. 33. No 7. P. 738-753. 
Munoz de Bustillo R., Fernandez-Macias E., Anton J.-I., Esteve F. (2011) Measuring More than Money: The Social Economics of Job Quality. Cheltenham: Edward Elgar.

Muntaner C., Li Y., Xue X., Thompson T., O'Campo P., Chung H., Eaton W. W. (2006) County Level Socioeconomic Position, Work Organization and Depression Disorder: a Repeated Measures Cross-classified Multilevel Analysis of Low-income Nursing Home Workers. Health Place. Vol. 12. P. 688-700.

OECD (2013) Well-being in the Workplace: Measuring Job Quality. How is Life? OECD Publishing. P. 150. URL: http://dx.doi.org/10.1787/9789264201392-en (accessed: 12.02.2021).

Saint-Hilaire F. (2008) Mental Health at Work: The Relational Side. Québec: Université Laval.

Servant D. (2013) Le Stress au travail: Prévention et prise en charge en thérapies comportementales et cognitives. Issy-les-Moulineaux: Elsevier Masson SAS.

Siegrist J., Starke D., Chandola T., Godin I., Marmot M., Niedhammer I., Peter R. (2004). The Measurement of Effort-Reward Imbalance at work: European Comparisons. Social Science \& Medicine. Vol. 58. No. 8. P. 1483-1499.

Vézina M., St-Arnaud L., Laliberté D., Maranda M. F., Gilbert M. A. (2008) Demands in Caring Professions. JCQ 2.0 International Workshop. Québec. September $5^{\text {th }}$.

Wännström I., Peterson U., Åsberg M., Nygren Å., Gustavsson J. P. (2009) Psychometric Properties of Scales in the General Nordic Questionnaire for Psychological and Social Factors at Work (QPSNordic): Confirmatory Factor Analysis and Prediction of Certified Long-term Sickness Absence. Scandinavian Journal of Psychology. Vol. 50. P. 231-244. 